\title{
SHIFTING BETWEEN CULTURAL IDENTITIES: THE VOICE OF PRESCHOOL CHILDREN
}

\author{
MARIA CRISTINA POPA
}

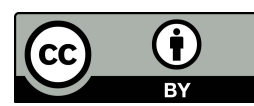

Faculty of Social and Human Sciences, University Lucian Blaga of Sibiu

5-7 Bd. Victoriei, Sibiu, Romania

E-mail address: mariacristina.popa@ulbsibiu.ro

\begin{abstract}
Aim. The purpose of this research is to capture the shift between two cultural identities, for a group of Romanian children enrolled in a German teaching preschool class, and to closely analyse the impact on cultural identity components.

Methods. In this study 27 children, aged 3 to 6, were involved, together with their parents and two teachers. During one year of investigation, they were analysed using participative observation, focus groups and in-depth interviews conducted in a public preschool.

Results. The analysis reveals which cultural identity components of these children undergo transformation, in what amount and with what impact considering the school environment and the influence of both parents and teachers. For this research, the exploration of cultural identity components was done under the conceptualisation proposed by Ching Wan and Pony Yuen-Ga Chew (2013), namely: cultural knowledge, categorisation and social relationships (self-expressed in attitudes and behaviour).

Conclusions. Although a positive image emerges for the German culture as a future culture of belonging, we notice the children's effort to achieve the cultural shift desired by their parents and a subtle emotional discharge in their free play and verbalised mental models. The different vision of parents and teachers over education strengthens some components of cultural identity by broadening the autonomy-shame ambition that increases the level of self-confidence, which receives a distinct German cultural mark.
\end{abstract}

Key words: cultural identity components, ethnic labels, children's cultural awareness

\section{INTRODUCTION}

Identity can only be understood as a process of being and becoming, a process initiated somewhere between the need for similarity and difference and characterised by the dynamics of agreement-disagreement, conventioninnovation, and communication-negotiation (Jenkins, 1996). The construction of cultural identity no longer carries doubts over the process itself. The world is constantly moving and cultural blending, globally or individually, is both a challenge and a source of social regeneration.

Studying the effects that cultural blending on the state of together the individual well-being and the political and economic situation is a subject of inter- 
est in a world increasing cultural mix (Jana, Linda, Maja, \& Harald, 2018). For the most part, the literature in this area regards the problems of immigrants adapting to the new countries of affiliation (Cohen \& Kassan, 2018; Bhugra \& Becker, 2005). Henri Tajfel and John Turner (1979) proposed strategic explanations if the membership group did not meet the need for preserving one's positive social identity. The authors propose three strategies: (1) social mobility, (2) social creativity and (3) social competition.

Most researches aim at the adolescent and adult population, who subscribe to one of these social mobility strategies. This study explores two different perspectives. First, the subjects analysed are children. Second, the context in which the discussion arises is one in which although one of the mentioned strategies is adopted, neither immigrants, nor minorities adopt the creative strategy for the improvement of their social-cultural identity, but the majority. The cultural mix space we are considering in this research is Transylvania (and the city of Sibiu), a place with more than 800 years of history of ethnic interference. Although the majority of population is of Romanian ethnicity and the German/Saxon is a minority, the past Saxon state's superiority (Gündisch, 2001) is preserved over time and infused into the prestige of the German school (Popa, 2007). Today, in Sibiu, the public school has a Romanian section and a German one. And the Romanian parents want to enrol their children in the prestigious German section. This study explores the voice of children under the parents' decision of enrolling them in a German section preschool and the effects on their cultural identity components.

The most common components through which cultural identity is described are: ethnic or national in origin, religion, race, gender, language, country, education, occupation, age, family and status (Altugan, 2015).

Farah Ibrahim and Jianna Heuer (2015) complete the list with the following: race, ethnicity, nationality, migration and indigenous status, migration as a phenomenon in the membership group, dominated or domineering status of the membership group, socio-political history, gender and sexual orientation, socio-economic status of family, religion and spirituality, level of education, family characteristics (number of parents, other close members, single parent family), capacity and disability of the social status, country and region of origin, and residence of the moment.

For this study, the analysis of the cultural identity components subscribes to the conceptualisation recommended by Wan Ching and Pony Yuen-Ga Chew (2013), namely: cultural knowledge, categorisation and social relationships (self-expressed in attitudes and behaviour).

As the history just listed does not generate a profound understanding of social transformation, which in turn supports the calibration of future interactions and the well-being at micro and macro level, nor the inventory of cultural identity components is sufficient. This study looks deeply at the changes within the cultural identity from an early age with a still in formation psychology and tries to obtain authentic feedback directly for children's voices. 
Lourdes Gaitán (2006) proposes a new sociology of childhood and attributes the role of active social actors to children (as a group unit, not to the child as an individual unit), which must be taken into account in sociological approaches. What the new researcher's theory brings out is the description of the two institutions, the family and the school, in terms of the significance that children assign (Gaitán, 2006).

The argument for the "children's voice" perspective is the direction of the triad family-sociocultural environment - children, which "will be positive when the characteristics of the children and the parents are compatible or congruent, and the response to social support is adequate" (Gaitán, 2006, p. 27). Coherence within this matrix is considered important for social balance. However, unlike the past, today taking into account the children's perspective as a valued social group in the contemporary society is imposed more than in the manner of a right. The need to understand children as factors in themselves is postulated to contribute to the construction of the social system through their active participation in establishing consistency (Gaitán, 2006).

\section{METHODOLOGY}

The research was conducted during one year, using participative observation, focus groups and in-depth interviews. Research tools such as an interview guide for focus groups and observation grids were used. We emphasise that this study is descriptive and non-experimental. The target population was a group of children from a public kindergarten. For completing and understanding the data collected, the two teachers from the observed group were also interviewed.

12 boys and 15 girls, aged 3 to 6 , formed the group of investigated children. Usually, kindergarten classes gather children of the same age, but the German section uses mixed aged classes as a learning strategy (toddlers learn from the ones that are of a superior age). The group has no special requirements and no physical or psychological issues are mentioned.

Children's parents are of different ages, starting from 24 to 55 years, and have diverse occupations (economist, professor, doctor, engineer, administrator, computer operator, lawyer, non-commissioner, translator, etc.).

The two teachers are graduates of the high school, the German section, have completed higher education in the field of foreign languages (German-English, German-Romanian) and have a five-year and a 27-year experience in preschool education.

\section{Hypothesis}

The configuration of cultural identity components of the observed children undergoes changes that they do not comprehend, but can be converted into adverse emotional states. 
Research questions

1. Are children aware of the differences between Romanian and German cultural elements?

2. Are children able to label different ethnicities? What are those labels?

3. What is the role of free play in this context of cultural identity construction?

4. What is the autonomy-shame conjunction and what effects does this configuration have on the cultural identity of children?

The cultural identity components are detailed in Table 1 as study dimensions and variables.

Table 1. Dimensions, variables

\begin{tabular}{ll}
\hline Dimensions & Variables \\
\hline Cultural knowledge & $\frac{\text { Ethnicity }}{\text { Cultural symbols }}$ \\
\cline { 2 - 2 } & $\frac{\text { Language }}{\text { Holidays }}$ \\
\hline Categorisation & $\frac{\text { Internalisation }}{\text { Self in social relation (expressed in attitudes and behaviour) }}$ \\
\cline { 2 - 2 } & Autonomy \\
\cline { 2 - 2 } & Shame \\
\cline { 2 - 2 } & Guitiative \\
\hline
\end{tabular}

Source: Author

\section{RESEARCH ETHICS}

Prior to starting the study, parents/legal tutors were informed about the purpose and duration of the research, questions were answered and all the parents/legal tutors signed a detailed informed consent. An agreement was also signed with the kindergarten management and the County School Inspectorate Sibiu.

Regarding the direct consent of children, we note that filming and recordings were only done with their consent. If they have expressed verbal or nonverbal dissent in any situation, if the devices or mere presence/conversation has created discomfort, they have not been filmed, recorded or approached.

The names of the children and teachers used in the study are not real. The age of children, placed in brackets, is real. All citations presented as arguments for the interpretation of the results are personal communications taken from focus groups, interviews, and participative observation. Citations are placed between quotation marks and may have attached names which, we emphasise, are not real. 


\section{RESULTS AND DISCUSSION}

Results collected throughfocus-groups: Cultural knowledge and categorisation

Six to nine children participated in focus groups. In forming the groups, we respected the mix and friendships. In each group, both girls and boys were invited 3-4 years and 5-6 years and at least one child in the group's nucleus.

Focus groups were conducted after participatory observation. At this time, preschoolers know the role of the researcher and do not confuse it with that of teachers or other adults in the kindergarten. The conversation during focus groups was in Romanian.

The presentation of the results will be done following the cultural identity components, namely ethnicity, nationality, birthplace, gender, age, socio-economic status, family, language and religion. The data is taken from the information provided by the educator and from the documents made available by them.

Ethnicity: one German, two Hungarian, 24 Romanians

Nationality: all with Romanian nationality

Birth place: Sibiu

Gender: 15 girls, 12 boys

Age: three to six

Socio-economic status: Children come from families that, as teachers say, have a medium-to-high socio-economic status.

Religion: two Catholics, 25 Orthodox.

Family: Children's parents have diverse professions (economist, professor, doctor, engineer, administrator, computer operator, lawyer, non-commissioner, translator, etc.). Of the 27 children, three have separated or divorced parents. With one exception, educators do not specify any problem or special situation of any child.

Language: Romanian is the mother tongue for 25 children out of the 27 . Two have their native Hungarian language. Of the 54 parents (mother and father), eight speak German, and teachers evaluate their level of speech as relatively low. Valerio's mother (5 years) is one of the exceptions and she is also a German language teacher.

As far as the level of German language is concerned, educators appreciate that 11 of the children speak very well, seven only understand, but they don't speak. Of those who speak. The category of German-speaking parents is distinguished. These are part of past generations, educated in German schools.

\section{Cultural heritage}

At this point, the discussion will follow the questions addressed to children in focus groups. We will focus here on knowledge and awareness of familyspecific cultural elements and those practiced in the kindergarten environment. We also consider the ability to label, with specific nuances, and internalize the prestige of being in the German section. 
Knowledge about ethnicity and ethnic labels

Children's responses regarding their ethnicity are grouped into two categories: group and individual responses. Group responses depend on the leader's first statement. So when Victoria (6 years old, group leader) states "German!" the rest follows her. If they are asked in turn about their ethnicity, the children say they are "Romanians" (Antonia, 5 years old) or "Romanians and Germans" (Roxana, 5 years old).

A general feature is easily revealed: children are not aware of their ethnicity. Labels are retrieved from received information but are not internalized.

During the discussion, children attribute themselves, from the variants listed, different nationalities and ethnicities. They say they are American, Spanish, German, Romanian, but not Gypsies.

"Gypsies demand money from people!" (Antonia, 5 years old)

"Gypsies are the worst! Because they're wandering in the street. With broken clothes!" (Radu, 5 years old)

Ask "What is it better to be? Romanian, German, American, Gypsy ... ", pre-schoolers mostly choose the German option. Valeriu (5 years old) says "German!" raising his index finger.

In children's mental image, the German looks "Like a man! As a true man!" (Ruxandra, 5 years), and being Romanian means "to be a man who knows how to speak only Romanian" (Dumitru, 6 years), "a man who learns German" (Antonia, 5 years old) and "... to be good and listen" (Teodor, 5 years). Lustiness and obedience are often associated by the little ones with the idea of being Romanian.

Children speak of Germany as a destination, proudly state that they have visited the country and claim that "There, in Germany, there are buses of another colour!" (Mihai, 4 years old).

\section{Knowledge about symbols}

Children recognize both the flag of Romania and Germany.

\section{Knowledge of language}

Children know how to name the languages they speak. They say that at the kindergarten they speak German, and at home, as the case may be, Romanian, German, English, and the list receives colourful additions. Pre-schoolers say they speak with their parents French, English, Spanish and other invented languages.

Those who say they speak German at home and whose colleagues know they cannot really express themselves in German are quickly corrected. Filming after the end of a focus group captures a conversation between two children in which one threatens another to tell his mother that he has lied about speaking German at the kindergarten. "Good! Tell me! Mother knows I speak Romanian too!", says Iris (4 years), trying to soften the untrue statement.

Those who speak German present this feature as a compliment to their own person. "I already know German," says Valeriu (5 years). Knowing German 
is a fact for which they receive praise from teachers. "When we know a lot of German and we are careful," they are praised, says Ruxandra (5 years).

Valeriu (5 years old), a German teacher's son, remarked among her parents by her high attitude displayed at meetings at various events, says: "I am crazy about my mother saying all day long I can only speak German!".

\section{Knowledge about holidays}

Children do not give importance to celebrations and practices of this nature. The events (St. Martin's Day, Carnival etc.) are simple activities.

\section{Internalise the prestige}

Children know that they are "from the German class" and they consider themselves different because of this. No real awareness is revealed, but they carry on the prestige of being enrolled in a German lass.

Asked what they like about the German class, especially those who came from the Romanian section say they like to play. In fact, playing, colouring, going out, and sleeping are the most enjoyable activities mentioned by preschoolers. Viewed only in this section of research, preferences are normal for the respondents' age, but related to observing free play and the issues retained there, the conclusions have other valences.

Florentina (4 years) proudly states that she has "moved here". Everyone presents verbally or in visible attitude the pride of being in the German class.

The struggle of being in the German group is also verbalized. Children have the ability to put in words emotional states. "I do not like the German section .... Mmm ... my slippers don't want to come here!", says Elena (5 years old). "I do not like when I come to the kindergarten because my hair hurts!" (Iris, 4 years old). Elena (5 years old) responds it is difficult and "...I do not know a lot of German". The burden of those who do not speak the language is noted by colleagues who do speak German. Teodor (5 years) says about Doru (3 years) that "For him it is harder. He does not know German". Antonia (5 years old) confesses frankly, briefly and with tears in her eyes: "It's hard for me."

Results collected through participative observation and in-depth interview - Self in social relation (expressed in attitudes and behaviour)

The two teachers of the class observed are graduates of the high school, the German section, have completed higher education in the field of foreign languages (German-English, German-Romanian) and have a five-year and a 27-year working experience in education.

As far as the vision over education and the child is concerned, teachers argued that the German school offers a "model that you adapt to" (Ramona), learning it from teachers, from experience, from school organising in itself, and applying it (Ramona). The concept that synthesises the vision of the child's education, which the two educators share, is self-confidence.

"At the German section you give them another level of independence compared to the Romanian section," says Ramona, " $80 \%$ of what he does, is the 
child's choice, you support him, and somehow help him to affirm himself". "We try not to twist," Carmen says. Independence is not gained by letting children do what they want at any cost. There are rules, "not many", but "consistently pursued" (Carmen), which create discipline and "common sense".

"German style, yes. We do not sit with our elbows on the table, we do not crack, we do not stretch ... we talk at the table, we do not cry "(Carmen). Discipline is important. It is a tool for gaining confidence. The whole kindergarten space is available to children. But to gain access to what they want, children need to achieve the trust of teachers. And the confidence of the two teachers is gained by the evidence of self-confidence.

"You have to trust him from the beginning that he can, so he has confidence in himself." "And they like this" (Ramona). This is the maximum point that educators target. If the children come to discover that they can do things alone and, moreover, enjoy the little gains of independence, then they get to trust them and can rely on their abilities.

Trust is viewed as "natural" (Carmen), and the first model of how to gain their own self-confidence are the teachers themselves. They are models and a source of independence. Teachers constantly urge pre-schoolers to dress themselves, to choose toys, to go to the toilet, listen to colleagues' opinions, answer with arguments, ask for what they need, tell their opinions, speak German if they want to join the group. And their advice is followed. Children get to do what they are urged to do. Moreover, pre-school children are turning this challenge into a personal need. They want to dress themselves, choose their own toys, speak their opinion, etc.

Children see teachers as role models. Respect for them has several facades. First, it is a proof, with a disciplined tone, a combination of fear of punishment and action, which leads to gaining the confidence of teachers. Then there is an extension of the undisputed respect of parents regarding the status of teachers in the German section. It is also a fair source of feedback because it builds self-confidence through approvals. And last but not least, it is a consistent emotional factor.

"Because I give them freedom from the beginning, I give them decision power. I give them the tool in their hand. The rest is their decision", Carmen sums up, discovering a possible way of gaining self-confidence.

Here we discuss aspects of Bruner's theory (1970) with reference to the will to learn, which is related to the following factors: curiosity, aspiration to competence, self-modelling tendency in accordance with the process of identifying and engaging in the social reciprocity network.

The vision of educators meets with that of parents, who, when they come for their children, do not let them lie alone, get dressed, tell them what to do and especially what not to do, what not to say, and children fall into a state of comfort, under the guidance of security. "When they go out of the door, they dress themselves, and they [the children] sit on the chair. So the children manifest differently" (Carmen).

Educators mention their effort to adapt parents to the German vision and, at the same time, note their effort to assume that they have enrolled 
their children in the German section, a scenario that they "do not see up until the end" (Ramona). Teachers speak in interviews not about the difficulty of children to adapt, but about the strength that parents do in overcoming their own limits.

Another aspect highlighted by Ramona is the guilt of parents, the remorse that they feel when they come to kindergarten for their children. Conscious of the effort of children to shift in between two cultural education models, seeing them tired after a day of kindergarten, parents feel the need to spoil them by dressing them, accepting any of their requests. But, the teacher asks: "Why bother to help him when he enjoys doing it?"

The guilt that Ramona sees is also an effect of the new parental vision, which Baumeister (1986) emphasises. Parents do not know how to manage the new vision. And the situation becomes even more problematic if different practices are encountered to counter it. Parents come to educate their children to be something they are not (Dencik, 1992). The need for the uniqueness of children of the new identity (Baumeister, 1986) finds no support from parents to understand the process of constructing cultural identity because the processes do not resemble and do not have the same coordinates.

The views about adapting to a new cultural environment are divided. On the one hand, we have parents who do not seem to notice problems of the child adaptation to German kindergarten. On the other hand, we have the views of the teachers. Ramona sees the adaptation of children as a difficult period in which "most are scared." "It's just terrible to put yourself in a situation," she adds. In order to argue, the teacher adds to the well-known reasons for entering the community the language barrier. The newcomers in the group suddenly hear an unknown language, which they are urged to speak.

Ramona noticed that children adopt strategies. The sooner they find playmates, the faster the integration in the group.

There is also a point of transition to a genuine relaxation. "The shift is when the child says: I can do it myself, it is okay. I think here is a click and the child becomes more dominant about himself, he feels he can do it alone" (Ramona). Thus, adaptation depends on the independence of the child, independence that is otherwise urged to be won as quickly as possible to strengthen selfconfidence. More than urged, the child is placed in situations where he must do things himself. For example, dressing, undressing, going alone in the group room, brushing his teeth alone, deciding how much toothpaste to use, deciding what toy it wants to play with, etc.

\section{Free play}

In analysing free play, the first observation is that children play all over the classroom space, including the toilet. Free play periods range from 30 minutes to 1 hour. Allotted time is not scattered. Apart from Ovidiu (3 years), all children are looking for their playmates as soon as they are allowed to play freely.

Children use exclusively Romanian language in free play. Romanian, as Carmen concludes, is "the language of play". She also says, "These children 
have to express themselves. In which language do you better talk if not in your mother tongue?"

Both teachers are aware of the importance of the mother tongue and its role in the natural expression of children, majority Romanians.

Educators notice pre-schoolers' efforts to learn German. In their opinion, preschool children go through three stages in acquiring language skills. In the first year, children just get used to their spoken language. In the second, they begin to understand, and in the third, to speak. That is why they are reluctant to enrol children after the age of four, because they will leave the kindergarten without going through the three stages. And if time is offset by meditation and further training, children go through a difficult language acquisition process and their effort is not positively evaluated by teachers.

In focus groups, children in this category translate the extra learning effort into "slippers who do not want to go to kindergarten" or frustration with their mother (German teacher) who speaks "all German!" (Valeriu, 5 years old).

When asked to speak in German, even those who do, before expressing themselves, have a very short moment of pause imbued with shame. Shame is all the more noticeable as the language level decreases. Most of the time, those asked to answer in German and who do not know how to do it, end the conversation quietly, and the educator translates for them into what they think they intended to say.

In free play, problems disappear because the little ones address each other in their mother tongue. Children's actions seem to come out in an expected order.

Children play age-specific games with varied roles and scenarios commonly encountered during the pre-operative period and the concrete operations. Two scenarios stand out. First, the construction of towers as high as possible. Here competition is the basic idea. The tallest tower was built together with one of the teachers and reached the ceiling. After the tower was built, children always tried to achieve this performance.

And the second one is proposed by Veronica (6 years old), a girl struggling to adapt to the group, although she has been in this class for two years. The child has gone through the divorce of parents, is emotional and refuses to engage in activities. In free play it is different. Veronica proposes to older girls the game of puppies, in which she is the main character. Veronica is stubborn to remain the leader of the dogs and does not relinquish to the position. Denial of the right of others to take over the leadership of the dogs can be a form of abusive entry into the group that fails to adapt. The girl's slow voice does not change during the game, she speaks to her colleagues almost in a whisper and is attentive to teachers who may find irregularities in her mischievous approach, which would be sanctioned based on the principle of cooperation, mutually adopted in the group.

Competition infiltrates all the activities of the children, including free play. However, the desire to join the group and the recognition they need (they want to be like the brave ones, who are associated with those who know German), 
makes pre-schoolers come to compromise and cooperation. "It happens to us at that point [of cooperation]," Ramona asserts, referring to an authentic level of cooperation, not a compromise.

The free play of children is noisy. Erikson $(1965$, p. 25) assumes that children have "the ability to express in a spatial configuration what they do not dare or dare to say". The high attendance of pre-schoolers contributes to the noise of the group, especially during free activities. More than this, the moments of play bear the expression of release, including verbally (and we associate the language used in the game, that is, the Romanian language in which they can express themselves naturally), but also physically.

\section{Autonomy-Shame/Doubt}

Children's tasks and the urge to execute them are identifiable early on. The small independence linked to personal needs strengthens their confidence in their own capabilities. The youngsters come quickly to no longer depend on an adult to dress themselves or to go to the toilet. These purchases are counted in the personal development economy, being visible in the free play. They do not depend on the educator to get the toy they want, and if they need help to take a toy they express their desire urgently.

Competition, is inevitably met in a mixed group, but also used as a lever for transmission of knowledge, generates doubt and shame, because it always takes into account those among whom they want to stay and want to be recognised.

\section{Initiative-Guilt}

The initiative in games, resulting from the self-confidence, is in relation too with competition and the colleagues in the core of the group. Children with initiative are loved, relaxed, and active. They also develop rivalries and are jealous. Victoria and Antonio, the leaders of the group, are the ones who have most initiatives. They propose game ideas, they gather colleagues in a circle when they need to be counted, and they organize the collection of toys. Because their level of German is good, the initiative is associated with those who have this feature. By comparing them, there is an intrinsic processing of guilt, which determines the behaviour of both the deprived and those who are active. Victor ( 5 years) is surprised to console Ovidiu ( 3 years old) who is crying at a time of trouble in solving a construction game. The empathy of the older boy is impressive.

From the other direction, the guilt of the youngest or the new entrants has a much more personal touch. They are in competition with themselves in becoming the best, boasting allowing them to control the game, to be affiliated and to be close to the model they are aiming at. The process is not easy. Frustration of the unhappy is observed in the silence of free play, in listening to initiatives from leaders. By contrast, those in the nucleus are much more vocal, louder and more imposing. The situation will change with time when the little ones will take over and will be themselves part of the core of the group. 


\section{SUMMARY OF FINDINGS}

\section{Validation of hypothesis}

The main hypothesis is validated. The configuration of cultural identity components of the observed children undergoes changes that they do not comprehend, but can be converted into adverse emotional states.

\section{Research questions}

1. Are children aware of the differences between Romanian and German cultural elements?

From the data collected through focus groups we can conclude that although pre-schoolers know how to name the languages they speak, they recognize the flag of Romania and Germany, and know different aspects of the practice of home and kindergarten, they are not aware of them and do not separate them, neither under the imprint of a label.

2. Are children able to label different ethnicities? What are those labels?

Pre-schoolers label the different ethnic groups, but the labels are picked up from teachers' and parents' speech and attitude. Regarding the perception of being enrolled in the German section, it is remarked that children internalise the prestige of being in the German group.

3. What is the autonomy-shame conjunction and what effects does this configuration have on the cultural identity of children?

Children's autonomy is built through early responsibility. The young are urged to gain as early as possible their independence in terms of personal needs, but also by free expression of their own opinions. Shame comes from disobedience and has three sources. First, the negative attention of colleagues with whom they compete to be the best. The idea of doing it is, on the one hand, an extension of the parents' desire, and on the other hand, a need for appreciation from the teachers. The second source is intrinsic. Pre-schoolers notice an early sensitivity to the benefits of personal independence and do not want to lower their level with small compromises in the presence of parents. And the third source is the need for affiliation to the group through play and the attraction to the core of the group that tempers their competition. Sources generate both positive feelings and frustrations. The shift between autonomy and shame, with the specified nuances, makes self-confidence build up at an early stage.

4. What is the role of free play in this context of cultural identity construction? The free play initiative is a result of self-confidence, enthralled by the competition and model of teachers and peers in the core of the group. Along with the initiative, the guilt is seen in two forms. First, in the form of desire that increases the frustration of the need to win and do things on their own. Then, in the form of the way, especially by those new to the group, towards the appreciation of teachers and becoming according to the model of the colleagues in the core of the group. In both forms, we 
are talking about the fault attributed and auto-attributed to the self in the case of the inability to win, to do it themselves, to receive appreciation, to become the best/the brave/those who know German.

\section{LIMITATIONS}

Among research limitations we mention:

- Low recording quality; the sequences captured are regarded as arguments and sources of explanation for the subject being treated, not for artistic value. The researcher does not have technical skills.

- The recordings were made only by a researcher, so the prospect bears its vision.

\section{CONCLUSION}

Education, according to Jerome Seymour Bruner (1996), is not just a technical matter of good processing and transmission of information, it is a complex game of cultural matching with the needs of its members and vice versa. Essential bridges created by the connection between the members of a culture and their culture require coherence. Continuous negotiation with external cultural constraints is our way of complying with the present and of understanding and justifying the future we are planning (Bruner, 2006). So, compliance and negotiation are part of the process of building our cultural identity. And harmony must not be sought in the image of constraints in general, but in the nuances they receive in the process of building cultural identity.

The study only examines present issues. We can only project the importance of this model of building the cultural identity of children when they are mature. However, we can note the frustrations that pre-schoolers go through to meet their parents' desire to be in the German section, and the inner conflict due to the reverse relationship between frustrations and the benefits of personal independence gained earlier.

Above the whole process and the daily reality that children live in, we are surprised the fault attributed and auto-attributed to the self in case loosing, the constant need to receive appreciation, to become as those who know German. The observed children go through an early development that sends them to the state of diligence earlier. Here we can outline disharmonic nuances caused by the high level of frustration and the superiority attributed to the affiliation to the German section, but again covered by fault, fear of failure, exclusion or failure to meet expectations. 


\section{REFERENCES}

1. Altugan, A. S. (2015). The relationship between cultural identity and learning. Procedia - Social and Behavioral Sciences, 186, 1159-1162. doi:10.1016/j.sbspro.2015.04.161.

2. Baumeister, R. F. (1986). Identity: Cultural change and the struggle for self. New York: Oxford University Press.

3. Bhugra, D., \& Becker, M. A. (2005). Migration, cultural bereavement and cultural identity. World Psychiatry, 4(1), 18-24.

4. Bruner, J. S. (1996). The culture of education. Cambridge, Mass: Harvard University Press.

5. Bruner, J. S. (2006). La culture, l'esprit, les récits [The culture, the spirit, the stories]. Enfance [Childhood], 58(2), 118-125. doi: 10.3917/enf.582.0118.

6. Ching, W. and Chew, P.Y. (2013). Cultural knowledge, category label, and social connections: Components of cultural identity in the global, multicultural context. Asian Journal of Social Psychology, 16, 247-259. doi: 10.1111/ajsp.12029.

7. Cohen, J. A., \& Kassan, A. (2018). Being in-between: A model of cultural identity negotiation for emerging adult immigrants. Journal of Counseling Psychology, 65(2), 133-154.

8. Dencik, L. (1992). Creciendo en la era posmoderna: El niño y la familia en el Estado de Bienestar [Growing up in the postmodern era: The child and the family in the Welfare Stare]. Anuario de Psicologia [Yearbook of Psychology], 53, 71-91.

9. Gaitán, L. (2006). Sociología de la infancia [Sociology of childhood]. Madrid: Editorial Sintesis.

10. Gündisch, K. (2001). Autonomie de stări şi regionalitate în Ardealul medieval [Autonomy of states and regionality in medieval Transylvania]. În Transilvania şi saşii ardeleni în istoriografie. Din publicatiile Asociatiei de studii Transilvane Heidelberg [Transylvania and Transylvanian Saxons in historiography. From the publications of the Transylvanian Studies Association Heidelberg] (pp. 33-53). Sibiu: Editura Hora.

11. Ibrahim, F. \& Heuer, J. R. (2015). Cultural and Social Justice Counselling: Client-Specific Interventions. New York, NY: Springer.

12. Jana, V., Linda, J., Maja, K. S., \& Harald, W. (2018). Feeling half-half? Exploring relational variation of Turkish-heritage young adults' cultural identity compatibility and conflict in Austria. Identity, 18(1), 60-76. doi: 10.1080/15283488.2017.1410159.

13. Jenkins, R. (1996). Social identity. Londra: Routledge.

14. Popa, I. (2007). Învățământul Sibian. Repere istorice şi documentare [Sibiu Education. Historical and documentary milestones]. Bucureşti: Magister.

15. Tajfel, H., \& Turner, J. C. (1979). An integrative theory of intergroup conflict. In: W. Austin \& S. Worchel (Eds.), The social psychology of intergroup relations (pp. 33-48). Pacific Grove, CA: Brooks/Cole. 